\title{
Parameter Optimization of Ultrafine Comminution Based on Analytic Hierarchy Process: Fuzzy Comprehensive Evaluation
}

\author{
Zaisheng Zhu $\mathbb{D}^{1,2}$, Jinbo Zhu $\mathbb{D}^{1},{ }^{1}$ Yin Liu $\mathbb{D}^{1},{ }^{1}$ Huaizhi Shao $\mathbb{D}^{3}{ }^{3}$ Hongzheng Zhu $\mathbb{D}^{1}{ }^{1}$ \\ Chuanzhen Wang $\mathbb{D}^{1},{ }^{1}$ Jingyu Wang $\mathbb{D}{ }^{1},{ }^{1}$ and Yang Fan $\mathbb{D}^{1}$ \\ ${ }^{1}$ School of Materials Science and Engineering, Anhui University of Science and Technology, Huainan 232001, China \\ ${ }^{2}$ Panji Coal Preparation Plant, Huaihe Energy (Group) Co., Ltd., Huainan 232082, China \\ ${ }^{3}$ School of Resources and Environmental Engineering, Shandong University of Technology, Zibo 255049, China
}

Correspondence should be addressed to Jinbo Zhu; pgb2@aust.edu.cn

Received 14 October 2020; Revised 6 January 2021; Accepted 12 January 2021; Published 21 January 2021

Academic Editor: Radek Matušů

Copyright ( 2021 Zaisheng Zhu et al. This is an open access article distributed under the Creative Commons Attribution License, which permits unrestricted use, distribution, and reproduction in any medium, provided the original work is properly cited.

This paper proposes a fuzzy comprehensive evaluation of ultrafine powders, namely, yield and quality value-based feature selection. Three indicators reflecting product yield and quality were selected to construct a simple and practical fuzzy comprehensive evaluation protocol. The weight set of the indices and the fuzzy evaluation set were calculated based on the analytic hierarchy process (AHP) method. The fuzzy comprehensive evaluation value was worked out as the only comprehensive index for the evaluation of product. The best ultrafine comminution condition will be established through the comparison of the fuzzy comprehensive evaluation values. Single-factor experiments and orthogonal experiments of the main influencing factors of ultrafine comminution were conducted. It was concluded that the importance of each factor is sequentially the concentration, specific surface area (SSA) of the media, and percentage of critical speed (PCS). Moreover, the concentration and SSA of the media were equally important. Ultrafine comminution by ball mill had the best overall performance under the PCS of $85 \%$, the SSA of the media of $0.24 \mathrm{~m}^{2} / \mathrm{kg}$, and the concentration of $75 \%$.

\section{Introduction}

Grinding has been utilized in manufacturing fine and ultrafine powders for the development of new materials and for improving product quality $[1,2]$. The grinding technology can significantly affect the particle characteristics [3], but not a single-objective process [4]. It is difficult to pulverize the particles directly to required particle size, which generally includes pulverization and classification or prepulverization and ultrafine pulverization [5]. The grinding optimization has been studied in the fields of cement production, chemical industry, metallurgical fine grinding, mineral grinding, and other industries $[6,7]$. It can be seen that the proportion of the grinding cost is a large part $[8,9]$. Therefore, the study on grinding optimization is valuable and significant, so as to make the equipment have a better grinding response.

In order to solve the problem of multiobjective optimization, many scholars have established comprehensive evaluation criteria or methods, such as power coefficient measurement method, constraint method, and failure mode and effect analysis (FMEA) method [10, 11]. The optimization of the mineral ultrafine grinding process is a multiobjective optimization problem $[4,12]$. In many cases, the unit of measurement of each index is different. Therefore, it is difficult to objectively evaluate whether the optimized multiobjective problem is good or not.

Fuzzy set theory, introduced by Zadeh [13], resembles human reasoning in its use of approximate information and uncertainty to generate decisions. It was specifically designed to provide formalized tools for dealing with the imprecision intrinsic to many problems [14]. The fuzzy comprehensive evaluation method has been well applied in many fields $[15,16]$; however, it is less involved in the field of mineral crushing. In this study, the fuzzy comprehensive evaluation system, which is based on the analytic hierarchy process, was introduced into the field of ultrafine grinding; 
comprehensive indicators were used to optimize the ultrafine grinding process of mineral powders. The study aimed at optimizing the three main factors (the mass of powders smaller than $10 \mu \mathrm{m}$, the fractal dimension of particle size distribution and $d_{97}$ ) affecting the ultrafine grinding of mineral powders.

\section{Materials and Methods}

2.1. Materials. Potassium feldspar powders were used in this study, which were collected in Jiangsu Province. The $d_{97}$ of sample was $63.68 \mu \mathrm{m}$, and the particle size of smaller than $10 \mu \mathrm{m}$ was about $35.32 \%$, which was measured by a laser particle size analyzer (Model: BT-9300H). Sodium polyacrylate dispersant was purchased from the Chengxin Chemical Material Supply Station in Zhejiang Province.

2.2. Experiments. The samples were ground in a steel tank ball mill using the wet ultrafine pulverization method, by the ball grinder, with the rated power of $1000 \mathrm{~W}$ and the critical speed of $85 \mathrm{rpm}$. The ceramic tank with the inner diameter of $250 \mathrm{~mm}$, the inner height of $275 \mathrm{~mm}$, and the volume of 13.5 L were used. Two kinds of steel balls with the sizes of $12 \mathrm{~mm}$ and $17 \mathrm{~mm}$ were used in this experiment. Refer to previous research experiments [17]; the mass of ore powders was fixed at $3.66 \mathrm{~kg}$ at a slurry's mass concentration of $55 \%$ and the amount of dispersant was of $0.2 \%$ of the mineral powder weight. The specific surface area of the grinding media that consists of $6.6 \mathrm{~kg}$ of $12 \mathrm{~mm}$ steel balls and $28 \mathrm{~kg}$ of $17 \mathrm{~mm}$ steel balls was $0.20 \mathrm{~m}^{2} / \mathrm{kg}$. The operational percentage of critical speed was $95 \%$. The relevant data of the product ultrafine pulverized after $3 \mathrm{~h}$ were analyzed. A single-factor experiment was designed to analyze the main influence factors of the ball mill (rotation rate, SSA of the media, and concentration) in turn, and then the orthogonal experiments were designed to find the optimal process conditions.

2.3. Calculation of the Weight Based on AHP. Three indicators reflecting product quantity and quality were selected to construct a simple and practical fuzzy comprehensive evaluation scheme for ultrafine powders. The mass of powders smaller than $10 \mu \mathrm{m}\left(m_{-10}\right)$ was used to measure the yield. The fractal dimension of particle size distribution (PSD) and $d_{97}$ were chosen to measure the quality of the production.

The analytic hierarchy process established by Saaty [18] is a decision-making method combined qualitatively and quantitatively $[19,20]$. The function $f(x, y)$ indicates how important the indicator $x$ is compared to the indicator $y$; the function $f(y, x)$ indicates how important the indicator $y$ is compared to the indicator $x$. The values of $f(x, y)$ and $f(y, x)$ can be defined according to subjective judgment. If $x$ is as important as $y, f(x, y)=1$; if $x$ is especially more important than $y, f(x, y)=9$, and so on. $f(x, y) \in[1,9] ; f(y, x) \in[1 / 9,1]$.

Three indicators were compared pairwise, and the description matrix of importance is given as follows:

$$
\left[\begin{array}{cc}
\text { Equal } & \text { Evident } \\
\text { Equal } & \text { Between equal and evident } \\
& \text { Equal } \\
& \text { Equal }
\end{array}\right] \text {. }
$$

This description matrix is converted into a judgment matrix

$$
A=\left(a_{i j}\right)_{3 \times 3}=\left[\begin{array}{ccc}
1 & 5 & 4 \\
0.2 & 1 & 1 \\
0.25 & 1 & 1
\end{array}\right] .
$$

The judgment matrix is usually not a consistent matrix, and the consistency ratio should be calculated. The first eigenvalue of $A$ can be calculated according to the following equation:

$$
\lambda_{1}=\frac{1}{n} \sum_{i=1}^{n} \frac{\sum_{j=1}^{n} a_{i j} w_{j}}{w_{i}}
$$

where $\lambda_{1}=3.006$.

The consistency index CI of $A$ can be calculated according to the following equation:

$$
\mathrm{CI}=\frac{-1}{n-1} \sum_{i=2}^{n} \lambda_{i}=\frac{\lambda_{1}-n}{n-1}, \quad n=3,
$$

where $\mathrm{CI}=0.003$.

The consistency ratio CR can be calculated according to

$$
\mathrm{CR}=\frac{\mathrm{CI}}{\mathrm{RI}}
$$

If $\mathrm{CR} \leq 0.1$, it can be acceptable. When potential conflict emerges in evaluation [21], the CR is unacceptable and the decision-maker is encouraged to repeat the pairwise comparisons, or some approaches should be adopted to process highly conflicting data $[22,23]$.

From the relevant chart $[24,25]$, the index RI of the 3 dimensional judgment matrix is 0.58 :

$$
\mathrm{CR}=\frac{0.003}{0.58}=0.005<0.1 \text {. }
$$

Therefore, the judgment matrix $A$ is reliable and consistent.

According to the AHP theory, the weight vector is calculated using the power method, sum method, root method, and the characteristic roots method, among which the sum method is the simplest. In the case where the judgment matrix is consistent, each calculation method can obtain an accurate solution. The sum method was selected to calculate the weight vector in this study. The weight of each indicator is obtained through related calculation formulas. The weight of $m_{-10}\left(w_{1}\right)$ is 0.69 , the weight of $D\left(w_{2}\right)$ is 0.149 , and the weight of $d_{97}\left(w_{3}\right)$ is 0.161 , so the weight vector can be represented as $W=(0.69,0.149,0.161)^{\mathrm{T}}$.

2.4. Comprehensive Evaluation. The degree of membership $\mu_{1}$ of index $m_{-10}$ value was calculated by membership function $f\left(m_{-10}\right)$, degree of membership $\mu_{2}$ of index $D$ value 
calculated by membership function $f(D)$, and degree of membership $\mu_{3}$ of index $d_{97}$ value calculated by membership function $f\left(d_{97}\right)$, respectively. The membership functions $f\left(m_{-10}\right), f(D)$, and $f\left(d_{97}\right)$ are constructed in Section 3.1.1. The weight of $m_{-10}\left(w_{1}\right)$, the weight of $D\left(w_{2}\right)$, and the weight of $d_{97}\left(w_{3}\right)$ was calculated according to the AHP theory.

The construction process of the fuzzy comprehensive evaluation is shown in Figure 1.

\section{Results and Discussion}

\subsection{Application of Comprehensive Evaluation}

3.1.1. Evaluation Set and Membership Functions. The initial experiment conditions were set first. The ore powder slurry was prepared at $55 \%$ solid concentration by mass. SSA of the grinding media was $0.20 \mathrm{~m}^{2} / \mathrm{kg}$. The additive amount of dispersant was $0.2 \%$ of mineral powder. The PCS of the tank was $95 \%$. The result shows that $m_{-10}=2.656 \mathrm{~kg}, D=2.225$. According to PSD curve calculation, it can be calculated that $d_{97}=25.36 \mu \mathrm{m}$. Therefore, the evaluation set $U=\left(m_{-10}, D\right.$, $\left.d_{97}\right)=(2.656,2.225,25.36)$.

In the raw material, $m_{-10}$ was $1.293 \mathrm{~kg}$. And, the total mass of the raw material was $3.66 \mathrm{~kg}$, so the value range of the mass $m_{-10} \in[1.293,3.66]$. From geometric knowledge [26], the range of $D \in[1,3]$.

Ideally, when all raw mineral powders are pulverized to $-10 \mu \mathrm{m}, d_{100}$ was $10 \mu \mathrm{m}$ and $d_{97}$ was less than $10 \mu \mathrm{m}$. In this study, $d_{97}$ could be approximated as $d_{100}$, and thus $d_{97} \approx 10 \mu \mathrm{m}$. In the worst case, there were no fresh $-10 \mu \mathrm{m}$ powders formed in the product, so the upper limit of $d_{97}$ was $63.68 \mu \mathrm{m}$. Therefore, $d_{97} \in[10,63.68]$.

The kinetic equation [27], which has been revised by Aliavden [28], used to describe the grinding process of materials is obtained as the following equation:

$$
y(t)=y_{0} \exp \left(-k t^{n}\right),
$$

where $y_{0}$ is the initial sieve residue of ground materials with a certain particle size; $k$ is the grinding rate constant; and $n$ is the time index and determined by the property of ground material and its grinding conditions.

The comminution kinetics equation is as follows:

$$
y_{+10}(t)=84.76 e^{-0.64 t^{0.66}} \text {. }
$$

With the propelling of the ultrafine pulverization, the difficulty became greater. The second-degree parabolic membership function, which corresponded to pulverization kinetic curve [29], was selected. Because the indicator $m_{-10}$ was a benefit-type indicator, the larger the value, the better the product. While $D$ and $d_{97}$ were the cost-type indicators, the smaller the value, the better the product. Therefore, the membership functions used for the three indicators were different. The following formulas (equation (6)) are the membership functions of the indicators $m_{-10}, D$, and $d_{97}$ :

$$
\begin{aligned}
& f\left(m_{-10} ; 1.293,3.66,2\right)=\left\{\begin{array}{l}
0, \quad m_{-10} \leq 1.293, \\
\left(\frac{m_{-10}-1.293}{2.367}\right)^{2}, \quad 1.293<m_{-10}<3.66, \\
1, \quad m_{-10} \geq 3.66,
\end{array}\right. \\
& f(D ; 1,3,2)=\left\{\begin{array}{l}
1, \quad D \leq 1, \\
\left(\frac{3-D}{2}\right)^{2}, \quad 1<D<3 \\
0, \quad D \geq 3,
\end{array}\right. \\
& f\left(d_{97} ; 10,63.68,2\right)=\left\{\begin{array}{l}
1, \quad d_{97} \leq 10, \\
\left(\frac{\left(63.68-d_{97}\right)}{53.68}\right)_{2}, \quad 10<d_{97}<63.68, \\
0, \quad d_{97} \geq 63.68 .
\end{array}\right.
\end{aligned}
$$

3.1.2. Fuzzification and Comprehensive Evaluation. The values of indicators were changed into membership degrees - $\mu, \mu \in[0,1]$. Take one indicator of them, $m_{-10}$, as an example. In the product, $m_{-10}=2.656 \mathrm{~kg}$, and $1.293<2.656<3.66$, so the membership degree of $m_{-10}$ could be obtained by equation (6). 


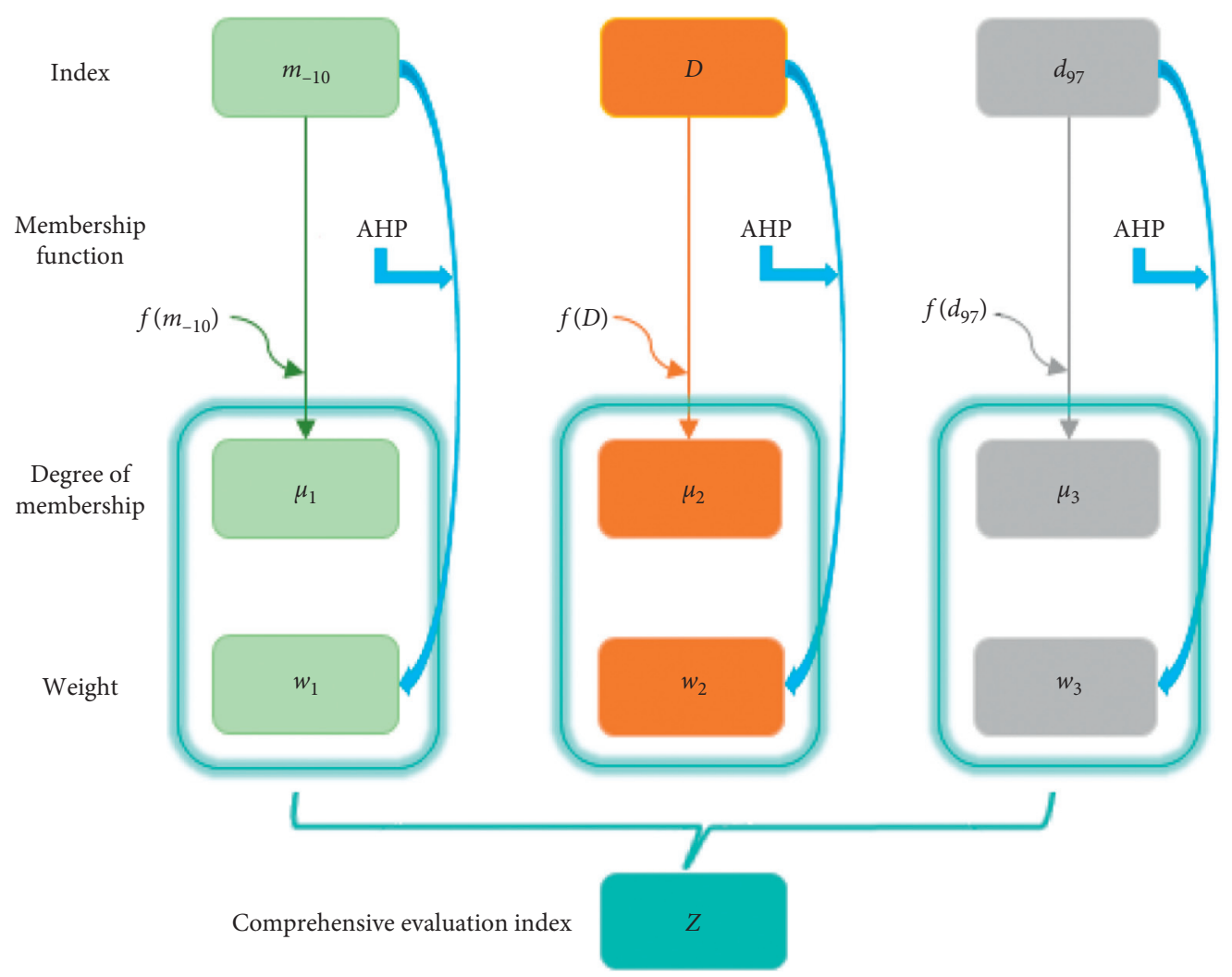

FIGURE 1: Flow chart of fuzzy comprehensive evaluation.

$\mu_{1}=f(2.656 ; 1.293,3.66,2)=\left(\frac{(2.656-1.293)}{2.367}\right)^{2}=0.332$

In turn, the membership degrees $\mu_{2}$ and $\mu_{3}$ of $D$ and $d_{97}$ could be calculated as 0.15 and 0.51 , respectively. The fuzzy evaluation set of each indicator is $U=(0.332,0.15,0.51)$ :

$$
Z=U_{1 \times 3} W_{3 \times 1} \text {. }
$$

According to equation (7), the multi-indicator fuzzy comprehensive evaluation value $Z$ can be calculated from the fuzzy evaluation set $U$ and weight set of each indicator $W$., where $U=(0.332,0.15,0.51)$ and $W=(0.69,0.149,0.161)^{\mathrm{T}}$; therefore, $Z=0.334$.

3.2. Effect of Factors on the Ultrafine Powders. The singlefactor experiment was designed to find the influence of single factor. Then, the orthogonal experiments were followed to analyze the best process conditions. Taguchi $\mathrm{L}_{9}\left(3^{4}\right)$ orthogonal arrays were generated by the IBM SPSS Statistics 25.0 .

3.2.1. Effect of PCS on the Ultrafine Powders. The best parameters of PCS were explored under the conditions where the operational concentration was $55 \%$ and SSA of the media was $0.24 \mathrm{~m}^{2} / \mathrm{kg}$. The results are shown in Table 1 .

When the experimental PCS was set to $85 \%$, the effect of ultrafine pulverization of mineral powders was best. With a gradual increase in the PCS, the fuzzy comprehensive evaluation value of the experiment results increased rapidly. After the curve reached the highest point, it gradually decreased, but the decrease of $Z$ value was not as rapid as before. When the PCS exceeded 100\%, the fuzzy comprehensive evaluation value of the results also dropped rapidly.

With the increase of the PCS, the movement of balls was changed from the principal tumbling form to the combinative impacting form and the tumbling form. The continuous increase of the PCS could cause the media to adhere to the wall, and the force on the particles would reduce. Changes of PCS changed the force distribution (impact force, shear force, frictional force, etc.) [30] between media and powders. The synthetic effect of several forces according to a certain distribution ratio made the possibility of particle refinement increase; thus, the effect was better.

3.2.2. Effect of SSA of the Media on the Ultrafine Powders. The best parameters of SSA of the media were explored under the conditions where the operational concentration was $55 \%$ and the PCS was $85 \%$. The different SSAs of the media were achieved by adjusting the ratio of the two different-sized media. The results are shown in Table 2 .

When the SSA of the media was $0.22 \mathrm{~m}^{2} / \mathrm{kg}$, ultrafine pulverization of mineral powders performs best. Small SSA of the media would greatly reduce the number of point contact among the balls, and the chance of the contact of slurry with grinding balls would be dramatically reduced [31]. During the movement of the media, although the 
TABLE 1: Variation of product feature at different speeds.

\begin{tabular}{|c|c|c|c|c|}
\hline $\begin{array}{l}\text { Product feature } \\
\text { PCS (\%) }\end{array}$ & $m_{-10}(\mathrm{~kg})$ & $D(-)$ & $d_{97}(\mu \mathrm{m})$ & $Z(-)$ \\
\hline 65 & 1.867 & 2.291 & 35.12 & 0.105 \\
\hline 75 & 2.154 & 2.263 & 32.68 & 0.165 \\
\hline 85 & 2.433 & 2.158 & 25.57 & 0.267 \\
\hline 95 & 2.447 & 2.325 & 29.14 & 0.248 \\
\hline 105 & 2.079 & 2.259 & 33.71 & 0.147 \\
\hline
\end{tabular}

TABLE 2: Variation of product features at different SSAs of the media.

\begin{tabular}{lccr}
\hline $\begin{array}{l}\text { Product feature } \\
\text { SSA of the media }\left(\mathrm{m}^{2} / \mathrm{kg}\right)\end{array}$ & $m_{-10}(\mathrm{~kg})$ & $D(-)$ & $d_{97}(\mu \mathrm{m})$ \\
\hline 0.20 & 2.190 & 2.262 & 33.07 \\
0.22 & 2.501 & 2.257 & 28.65 \\
0.24 & 2.433 & 2.158 & 25.57 \\
0.26 & 2.410 & 2.201 & 29.41 \\
\hline
\end{tabular}

impact force of a single ball on the material was increased, the frictional force and shear force were greatly reduced. The SSA of the media continued to increase, and the fuzzy comprehensive evaluation value of the product did not decrease greatly, which indicates that the impact force was not the main force. The friction force and shear force were the main forces in the pulverization process. In the late stage of ultrafine pulverization, the particles became round and the edges and corners basically disappeared.

3.2.3. Effect of Concentration on the Ultrafine Powders. The optimal concentration was explored under the conditions where the operational PCS was $85 \%$ and SSA of the media was $0.22 \mathrm{~m}^{2} / \mathrm{kg}$. The results are shown in Table 3 .

When the concentration was $65 \%$, the ultrafine pulverization of mineral powders works best. When the concentration was low, the PSD of product was narrow; however, the yield of product was low. In reverse, the PSD of product was extremely wide; although the yield of product had advantages, there were many large particles in the product, which affected the total quality. If the concentration was low, there were more opportunities for the occurrence of contact between the balls and the particles, but the contact between the particles was insufficient. When the concentration was too high, the liquidity of the slurry reduced sharply and the motion of balls and particles were obstructed, leaving some large particles uncrushed. According to "Bed comminution" [32], when there were more particles, there were more "particle-particle contact"; smaller particles would definitely be produced under the same pulverization condition. Therefore, an appropriate increase in the concentration would increase the fuzzy comprehensive evaluation value of the product.
3.2.4. Optimization Parameters. As shown in Table 4, the fuzzy comprehensive evaluation values of products were calculated. Due to the change in the concentration, the range of $m_{-10}$ changed. Thus, $m_{-10} \in[1.293,5.49]$.

The sequence of the factors influencing the product feature was listed by polar value analysis. With the indicator $m_{-10}$ as the appraising indicator, maximum differences $(R)$ of each factor were calculated orderly. $R$ (concentration $)=$ $0.994, R(\mathrm{PCS})=0.227, R(\mathrm{SSA}$ of the media $)=0.330$; the factors were ranked in order of importance, and concentration $>$ SSA of the media $>$ PCS. With the indicator $D$ as the appraising indicator, $R$ (concentration) $=0.181, R$ $(\mathrm{PCS})=0.130, R(\mathrm{SSA}$ of the media $)=0.163$, and concentration $>$ SSA of the media $>$ PCS. With the indicator $d 97$ as the appraising indicator, $R$ (concentration) $=17.817, R$ $(\mathrm{PCS})=6.343, \quad R \quad(\mathrm{SSA}$ of the media $)=5.233$, and concentration $>$ PCS $>$ SSA of the media. Obviously, the significance ordering of the factors was contradictory when choosing different appraising indicators. With the indicator $Z$ as the appraising indicator, $R$ (concentration) $=0.054, R$ $(\mathrm{PCS})=0.039$, and $R($ SSA of the media $)=0.053$. Concentration $>$ SSA of the media $>$ PCS; moreover, the concentration and SSA of the media were equally important.

Using the fuzzy comprehensive evaluation value as an indicator, combined with polar value analysis, the optimal process conditions were obtained. The optimal PCS should be at $85 \%$; the optimal SSA of the media should be at $0.24 \mathrm{~m}^{2} / \mathrm{kg}$ and the optimal concentration should be at $75 \%$.

Under the optimal conditions, a verification experiment was conducted to analyze the relevant parameters of the product, and the results are shown as follows: $m_{-10}=3.415 \mathrm{~kg}, D=2.483$, and $d_{97}=47.96 \mu \mathrm{m}$. Based on the membership function used in the orthogonal experiments, the membership degrees of each indicator were calculated, 
TABLE 3: Variation of product feature at different concentrations.

\begin{tabular}{|c|c|c|c|c|}
\hline $\begin{array}{l}\text { Product feature } \\
\text { Concentration (\%) }\end{array}$ & $m_{-10}(\mathrm{~kg})$ & $D(-)$ & $d_{97}(\mu \mathrm{m})$ & $Z(-)$ \\
\hline 45 & 1.913 & 2.154 & 23.98 & 0.145 \\
\hline 55 & 2.433 & 2.158 & 25.57 & 0.181 \\
\hline 65 & 2.674 & 2.258 & 30.14 & 0.182 \\
\hline 75 & 2.601 & 2.317 & 46.79 & 0.124 \\
\hline
\end{tabular}

TABLE 4: Results of the orthogonal experiments.

\begin{tabular}{|c|c|c|c|c|c|c|c|}
\hline No. & Concentration (\%) & PCS (\%) & SSA of the media $\left(\mathrm{m}^{2} / \mathrm{kg}\right)$ & $m_{-10}(\mathrm{~kg})$ & $D(-)$ & $d_{97}(\mu \mathrm{m})$ & $Z(-)$ \\
\hline 1 & 55 & 75 & 0.20 & 1.791 & 2.472 & 36.57 & 0.061 \\
\hline 2 & 55 & 85 & 0.22 & 2.501 & 2.257 & 28.65 & 0.146 \\
\hline 3 & 55 & 95 & 0.24 & 2.447 & 2.325 & 29.14 & 0.136 \\
\hline 5 & 65 & 75 & 0.22 & 2.583 & 2.464 & 39.21 & 0.109 \\
\hline 4 & 65 & 85 & 0.24 & 2.674 & 2.258 & 30.14 & 0.158 \\
\hline 6 & 65 & 95 & 0.20 & 2.464 & 2.532 & 40.45 & 0.092 \\
\hline 7 & 75 & 75 & 0.24 & 3.267 & 2.472 & 51.33 & 0.172 \\
\hline 8 & 75 & 85 & 0.20 & 3.148 & 2.54 & 49.29 & 0.154 \\
\hline 9 & 75 & 95 & 0.22 & 3.308 & 2.587 & 47.19 & 0.181 \\
\hline
\end{tabular}

$\mu_{1}=0.256, \mu_{2}=0.067$, and $\mu_{3}=0.086$. Finally, the maximum fuzzy comprehensive evaluation value under the optimal process parameters was obtained, $Z=0.200$. Therefore, the optimal operational factors obtained by polar value analysis were correct.

\section{Conclusions}

(1) Three indicators reflecting quantity and quality have been selected, and a comprehensive index has been constructed using a fuzzy comprehensive evaluation method based on hierarchical analysis, and this has been used to successfully find the optimal comminution operating conditions.

(2) The effect of different indicators on the ultrafine powders was analyzed with the AHP. The weight set of three indicators of $m_{-10}, D$, and $d_{97}$ was $W=(0.69$, $0.149,0.161)^{\mathrm{T}}$.

(3) The significance ordering of the factors of ultrafine pulverization was concentration, SSA of the media, and PCS. Moreover, the concentration and SSA of the media were equally important.

(4) When the optimal operating conditions were at the PCS of $85 \%$, the SSA of the media of $0.24 \mathrm{~m}^{2} / \mathrm{kg}$, and the concentration of $75 \%$, the comprehensive performance of the product was the best and $Z=0.200$.

\section{Data Availability}

The partial data used to support the findings of this study are included within the article, and other partial data are available from the first author upon request.

\section{Additional Points}

(1) The significance of three indicators of the ultrafine powders is analyzed by the analytic hierarchy process method. (2) According to the three indicators, the fuzzy comprehensive evaluation based on analytic hierarchy process is used to obtain the comprehensive indicator. (3) The three main factors influencing ultrafine comminution, concentration, specific surface area of the media, and percentage of critical speed are significantly ranked by the orthogonal test. The optimal operating conditions have been obtained subsequently.

\section{Conflicts of Interest}

The authors declare that there are no conflicts of interest regarding the publication of this article.

\section{Acknowledgments}

The authors gratefully acknowledge the financial supports provided by the National Natural Science Foundation of China (51374015); Natural Science Foundation of Anhui Province (2008085QE272); China Postdoctoral Science Foundation (2020M671837, 2019M662134); and Anhui Provincial Excellent Talent Project (gxyqZD2020019); The authors would like to extend their special thanks to Prof. Zhenfu Luo.

\section{References}

[1] S. Qu, Y. Gong, Y. Yang, M. Cai, H. Xie, and H. Zhang, "Grinding characteristics and removal mechanism of 2.5Dneedled Cf/SiC composites," Ceramics International, vol. 45, no. 17, pp. 21608-21617, 2019.

[2] B. Öksüzoğlu and M. Uçurum, "An experimental study on the ultra-fine grinding of gypsum ore in a dry ball mill," Powder Technology, vol. 291, pp. 186-192, 2016.

[3] S. Liu, Q. Li, and J. Song, "Study on the grinding kinetics of copper tailing powder," Powder Technology, vol. 330, pp. 105-113, 2018.

[4] H. Choi, W. Lee, J. Lee, H. Chung, and W. S. Choi, "Ultra-fine grinding of inorganic powders by stirred ball mill: effect of 
process parameters on the particle size distribution of ground products and grinding energy efficiency," Metals and Materials International, vol. 13, no. 4, pp. 353-358, 2007.

[5] G. Guosheng, Powder Engineering, Tsinghua University Press, Beijing, China, 2010.

[6] D. W. Chen, X. L. Ge, Q. Shi, and Y. Tian, "Study on the nonlinear ultra-fine grinding kinetics of calcium carbonate in stirred mill," Materials Research Innovations, vol. 19, no. sup5, pp. S5-S999-S5-1003, 2015.

[7] S. Nkwanyana and B. Loveday, "Addition of pebbles to a ballmill to improve grinding efficiency," Minerals Engineering, vol. 103-104, pp. 72-77, 2017.

[8] W. Xie, Y. He, Y. Yang et al., "Experimental investigation of breakage and energy consumption characteristics of mixtures of different components in vertical spindle pulverizer," Fuel, vol. 190, pp. 208-220, 2017.

[9] J. Duan, Q. Lu, Z. Zhao et al., "Grinding behaviors of components in heterogeneous breakage of coals of different ash contents in a ball-and-race mill," Minerals, vol. 10, no. 3, p. 230, 2020.

[10] M. Ehrgott, Multicriteria Optimization, Springer, Berlin, China, 2005.

[11] D. Wu and Y. Tang, "An improved failure mode and effects analysis method based on uncertainty measure in the evidence theory," Quality and Reliability Engineering International, vol. 36, no. 5, pp. 1786-1807, 2020.

[12] J. Zhao, D. Wang, X. Wang, S. Liao, and H. Lin, "Ultrafine grinding of fly ash with grinding aids: impact on particle characteristics of ultrafine fly ash and properties of blended cement containing ultrafine fly ash," Construction and Building Materials, vol. 78, pp. 250-259, 2015.

[13] L. A. Zadeh, "Fuzzy sets," Information and Control, vol. 8, no. 3, pp. 338-353, 1965.

[14] G. Zheng, N. Zhu, Z. Tian, Y. Chen, and B. Sun, "Application of a trapezoidal fuzzy AHP method for work safety evaluation and early warning rating of hot and humid environments," Safety Science, vol. 50, no. 2, pp. 228-239, 2012.

[15] Y. Zhang, R. Wang, P. Huang, X. Wang, and S. Wang, "Risk evaluation of large-scale seawater desalination projects based on an integrated fuzzy comprehensive evaluation and analytic hierarchy process method," Desalination, vol. 478, p. 114286, 2020.

[16] T. Guo, S. Tang, J. Sun et al., "A coupled thermal-hydraulicmechanical modeling and evaluation of geothermal extraction in the enhanced geothermal system based on analytic hierarchy process and fuzzy comprehensive evaluation," Applied Energy, vol. 258, p. 113981, 2020.

[17] Z. Zhu, "Ultra-fine grinding potassium shale processing technology with balling mill," in School of Chemical Engineering and TechnologyChina University of Mining and Technology, Xuzhou, China, 2012.

[18] T. L. Saaty, "A scaling method for priorities in hierarchical structures," Journal of Mathematical Psychology, vol. 15, no. 3, pp. 234-281, 1977.

[19] R. R. Tan, K. B. Aviso, A. P. Huelgas, and M. A. B. Promentilla, "Fuzzy AHP approach to selection problems in process engineering involving quantitative and qualitative aspects," Process Safety and Environmental Protection, vol. 92, no. 5, pp. 467-475, 2014.

[20] S. K. Mangla, P. Kumar, and M. K. Barua, "Risk analysis in green supply chain using fuzzy AHP approach: a case study," Resources, Conservation and Recycling, vol. 104, pp. 375-390, 2015.
[21] D. Wu, Z. Liu, and Y. Tang, "A new classification method based on the negation of a basic probability assignment in the evidence theory," Engineering Applications of Artificial Intelligence, vol. 96, p. 103985, 2020.

[22] M. Jing and Y. Tang, "A new base basic probability assignment approach for conflict data fusion in the evidence theory," Applied Intelligence, vol. 51, pp. 1-13, 2020.

[23] Y. Chen, Y. Tang, and Y. Lei, "An improved data fusion method based on weighted belief entropy considering the negation of basic probability assignment," Journal of Mathematics, vol. 2020, Article ID 1594967, 1 page, 2020.

[24] T. L. Satty, The Analytic Hierarchy Process, McGraw-Hill, NY, USA, 1980.

[25] R. E. Breaz, O. Bologa, and S. G. Racz, "Selecting industrial robots for milling applications using AHP," Procedia Computer Science, vol. 122, pp. 346-353, 2017.

[26] K. Falconer, Zeng, Wenqu Fractal Geometry: Mathematical Foundations and Applications, Posts \& Telecom Press, Beijing, China, 2007.

[27] S. F. Shinkorenko, "New equations for the kinetics of crushing and their use for calculating the output of ball mills," Soviet Mining Science, vol. 13, no. 4, pp. 382-388, 1977.

[28] S. Liu, Q. Li, G. Xie, L. Li, and H. Xiao, "Effect of grinding time on the particle characteristics of glass powder," Powder Technology, vol. 295, pp. 133-141, 2016.

[29] O. Celep and E. Y. Yazici, "Ultra fine grinding of silver plant tailings of refractory ore using vertical stirred media mill," Transactions of Nonferrous Metals Society of China, vol. 23, no. 11, pp. 3412-3420, 2013.

[30] D. Fan, Research on the Media Movement Form and Parameters of Ball Mill, Zhejiang University of Technology, Hangzhou, China, 2010.

[31] L. Chang, W. Wang, and $\mathrm{H}$. Ru, "Effect of ball milling parameters on the preparing ultrafine WC powders," Journal of Minerals, Metallurgy and Materials, vol. 18, pp. 207-212, 2019.

[32] M. Khanal, W. Schubert, and J. Tomas, "Discrete element method simulation of bed comminution," Minerals Engineering, vol. 20, no. 2, pp. 179-187, 2007. 